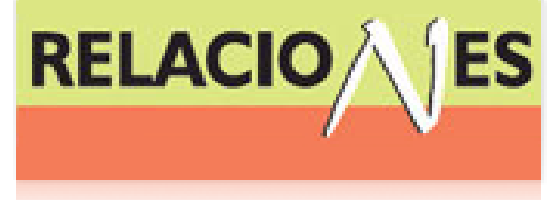

Relaciones. Estudios de historia y sociedad ISSN: 0185-3929

relacion@colmich.edu.mx

El Colegio de Michoacán, A.C

México

Preciado Zamora, Julia

El inicio de la conciliación entre la Iglesia y el Estado: el funeral del arzobispo de Guadalajara

Francisco Orozco y Jiménez

Relaciones. Estudios de historia y sociedad, vol. XXXI, núm. 124, 2010, pp. 55-90

El Colegio de Michoacán, A.C

Zamora, México

Disponible en: http://www.redalyc.org/articulo.oa?id=13718469003

Cómo citar el artículo

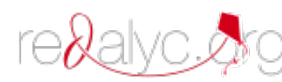

- Número completo

- Más información del artículo

- Página de la revista en redalyc.org

Sistema de Información Científica

Red de Revistas Científicas de América Latina, el Caribe, España y Portugal Proyecto académico sin fines de lucro, desarrollado bajo la iniciativa de acceso abierto 


\title{
EL INICIO DE LA CONCILIACIÓN ENTRE LA IGLESIA Y EL ESTADO: EL FUNERAL DEL ARZOBISPO DE GUADALAJARA FRANCISCO OROZCO Y JIMÉNEZ
}

\author{
Julia Preciado Zamora* \\ CIESAS-Unidad Occidente
}

El análisis de un funeral funciona como una especie de tragaluz que permite estudiar una época a través de la muerte y de la vida, de un individuo. En este artículo se estudia el funeral del arzobispo de Guadalajara Francisco Orozco y Jiménez (quien murió en esa ciudad en 1936), partiendo del contexto político y social de la década de los años treinta en Jalisco.

(Iglesia, siglo XX, estudio de funerales)

INTRODUCCIÓN

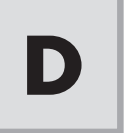

iferentes estudios han interpretado de varias formas cómo el Estado usa los funerales que organiza para sus grandes personajes. ${ }^{1}$ La disposición de un funeral de Estado no es simplemente una ceremonia en la que, más allá de la familia, el Estado se apropia de la muerte del personaje. La detallada planeación de un funeral persigue un desarrollo y objetivo precisos. Durante la Tercera República francesa los funerales eran una especie de festivales cívicos en los que el gobierno autocelebraba sus logros. ${ }^{2}$ A propósito de la muerte de Abraham Lincoln, los bien organizados eventos en los que se le despidió y homenajeó, lograron unir a los habitantes de Estados Unidos, quienes en el pasado reciente se hallaban divididos por los es-

\footnotetext{
*julia_preciado@yahoo.com julia@ciesas.edu.mx

${ }^{1}$ Un funeral de Estado es una ceremonia pública que homenajea a jefes de Estado, héroes nacionales o altos funcionarios de la administración.

${ }^{2}$ Avner Ben-Amos, Funerals, Politics, and Memory in Modern France, 1789-1996, Oxford, Oxford University Press, 2000.
} 
tragos de la guerra civil y sus secuelas. ${ }^{3}$ El funeral de Bernardo O'Higgins en Chile, aunque realizado 45 años después de su muerte, funcionó como un referente de la identidad nacional, al tiempo que concilió las diferentes opiniones políticas. ${ }^{4}$

A la muerte de Manuel Romero Rubio, suegro de Porfirio Díaz, le siguió un funeral de Estado que sirvió al régimen para impulsar la creación de nuevos héroes nacionales. ${ }^{5}$ En el funeral de Álvaro Obregón, se logró momentáneamente la unión de la familia revolucionaria. Mientras que en dos funerales que no pertenecen a los de la categoría de Estado -los de José de León Toral y Pedro Infante- ciertas particularidades de las ceremonias permiten concluir que las mujeres católicas retomaron el funeral del ejecutor de Obregón para protestar por las medidas anticlericales del Estado. ${ }^{6}$ En el funeral de Pedro Infante se escindieron las dimensiones de lo tradicional y lo moderno, transformación evidente en el México de la década de los cincuenta. ${ }^{7}$

En la bibliografía que estudia funerales de hombres famosos, hasta donde he podido establecer no existen estudios de personajes de la Iglesia católica. Es posible, sin embargo, retomar el análisis de los funerales de Estado para estudiar específicamente las ceremonias fúnebres de obispos y arzobispos. En el caso del arzobispo Orozco y Jiménez su funeral sirvió para iniciar la conciliación entre la Iglesia y el Estado. El arzobispo sucesor José Garibi Rivera, ${ }^{8}$ junto con la jerarquía de la Iglesia

\footnotetext{
${ }^{3}$ Barry Schwartz, "Mourning and the Making of a Sacred Symbol: Durkheim and the Lincoln Assasination, Social Forces 70.2, diciembre de 1991, 343-364.

${ }^{4}$ Carmen Mc Evoy, "El regreso del héroe: Bernardo O’Higgins y su contribución en la construcción del imaginario nacional chileno, 1868-1869", en Funerales Republicanos en América del Sur: tradición, ritual y nación, 1832-1896, editado por idem, pp. 125-155, Santiago, Centro de Estudios Bicentenario/ Pontificia Universidad Católica de Chile, 2006.

${ }^{5}$ Matthew D. Esposito, "Death and Disorder in México City: The State Funeral of Manuel Romero Rubio", en Latin American Popular Culture: An Introduction, editado por William H. Beezley y Linda A. Curcio, Wilmington, Scholarly Resources Inc., 2000, 87-103

${ }^{6}$ Amanda Marie López, "El manco y el mártir: Funerals, The Family, and Popular Memory of the Assassination of Álvaro Obregón, 1928-1929, Tesis de maestría, University of Arizona, 2004.

${ }^{7}$ Anne Rubenstein, “Bodies, Cities, Cinema: Pedro Infante's Death as Political Spectacle", en Fragments of a Golden Age. The Politics of Culture in Mexico Since 1940, editado por Gilbert Joseph, Anne Rubenstein y Eric Zolov, London, Duke University Press, 2001, 199-233,

${ }^{8}$ Para entender la actitud de Garibi Rivera es necesario conocer su "cercanía-distan-
} 
en Jalisco, organizó el funeral de Orozco y Jiménez apegándose estrictamente a las normas que dispuso el gobierno local. Garibi Rivera trató de mostrar, a través de las diferentes ceremonias del funeral, que la Iglesia tapatía estaba dispuesta a iniciar una nueva era de conciliación con el Estado, en una época en la que en el ámbito nacional estaba a punto de romperse el modus vivendi entre la Iglesia y el gobierno civil.

\section{OBISPO Y ARZOBISPO DURANTE LA REVOLUCIÓN}

Francisco Orozco y Jiménez nació en Zamora, Michoacán, el 19 de noviembre de 1864, al seno de una familia acaudalada. A los 12 años viajó, junto con Luis su hermano mayor, a Roma para estudiar en el Colegio Pío Latinoamericano. Permaneció en esa ciudad entre 1876 y 1888. En este último año regresó a Zamora y se convirtió en capellán del templo de San Francisco y de la hacienda de La Noria. Ocho años más tarde se doctoró en Sagrada Teología en la Pontificia Universidad de México. ${ }^{9}$ Como parte de su formación sacerdotal Orozco y Jiménez dominaba el latín, el griego, el italiano, el francés, el inglés y el portugués. Manejaba además con maestría su correspondencia privada y pública.

te" con Orozco y Jiménez. José Garibi Rivera (1889-1972) se convirtió en sacerdote en 1912. Un año después formó parte de un grupo de ocho estudiantes, de entre muchos tapatíos, a quien el recién llegado arzobispo Orozco y Jiménez envío (como él había lo hecho en su momento) a prepararse al Colegio Pío Latino Americano. Garibi Rivera regresó de Roma en 1916 y a partir de entonces se empeñó en varias actividades dentro de la Iglesia tapatía; dio clases en el Seminario Mayor en Guadalajara, y también se encargó de varias parroquias en la región de Los Altos. Poco a poco se acercó a la ciudad de Guadalajara para ocupar cargos importantes dentro de la administración de la arquidiócesis. En 1930, Garibi Rivera se convirtió en coadjutor del arzobispo. A partir de entonces compartió tareas y responsabilidades cada vez mayores con su superior inmediato. El 22 de diciembre de 1934, por Bula Pontificia y por petición de Orozco y Jiménez, se designó a Garibi Rivera arzobispo auxiliar con derecho a sucesión. Véase José Salazar, "Mons. Orozco y el Pontificio Colegio Pío Latino-Americano" en Homenaje a la memoria del Excmo. y Revmo. Sr. Dr. y Mtro. D. Francisco Orozco y Jiménez, arzobispo de Guadalajara, coordinado por J. Ruiz Medrano, Guadalajara, Imprenta Font, 1936, 157-162, 159.

${ }_{9}$ J. Ignacio Dávila Garibi, Apuntes para la Historia de la Iglesia en Guadalajara, vol. 5, México, Libros de México, 1977, 5:145. 
Más tarde cambió sus actividades de simple capellán en Zamora y emigró a la ciudad de México. Ahí fue profesor del Colegio Clerical de San Joaquín y del Seminario Conciliar. El 30 de mayo de 1902 el papa León XIII lo designó obispo de Chiapas, función que desempeñó hasta 1912. Este nombramiento tuvo que ver con la pertenencia de Orozco y Jiménez al grupo formado en el Colegio Pío Latinoamericano, institución que en 1858 fundó el arzobispo chileno Víctor Eyzaguirre. ${ }^{10}$ El Pío Latinoamericano nació con el objetivo de formar "un nuevo tipo de jerarquía clerical latinoamericana", instruida por profesores jesuitas de la Universidad Gregoriana. ${ }^{11}$ La creación del Pío Latinoamericano formaba parte del proceso de "romanización" que consistió en "la reforma eclesiástica del Vaticano" a través de la "centralización de las iglesias tendiente a fortalecer la autoridad de la jerarquía romana y del papado frente al poder que ejercía el clero local" ${ }^{12}$ El arzobispo de México, Pelagio Antonio de Labastida y Dávalos y el arzobispo de Michoacán, José Clemente de Jesús Munguía, apoyaron en su momento la creación del Pío Latinoamericano. El arzobispo Labastida impulsó además "la formación de una nueva generación de jerarcas mexicanos educados" en ese colegio. ${ }^{13}$ Entre dichos estudiantes se encontraba su sobrino José Antonio Plancarte, quien a su regreso a Zamora, Michoacán, envió a varios estudiantes a Roma, entre los que se hallaba Francisco Orozco y Jiménez.

Ese selecto grupo una vez en México aplicó con celo "el ritual romano", pero a su vez "se topó con la jerarquía clerical educada en las instituciones mexicanas, que se vio desplazada por la aparición de este nuevo grupo".${ }^{14}$ Hacia finales del siglo XIX este equipo ejercía gran peso en el episcopado mexicano. Además de Orozco y Jiménez, el grupo estaba

\footnotetext{
${ }^{10}$ Cecilia Adriana Bautista García, "Hacia la romanización de la Iglesia Mexicana a fines del siglo XIX", Historia Mexicana LV, 1, 2005, 99-144, 109.

${ }^{11}$ Ibid., 109.

${ }^{12}$ Ibid., 100.

${ }^{13}$ Ibid., 120.

${ }^{14}$ Años después en 1899 cuando se celebró el Concilio Plenario de América Latina, el Pio Latino se convirtió en la sede del evento que reunió a la curia latinoamericana. En el concilio se acordó que los obispos latinoamericanos protegerían económicamente al Colegio, además de comprometerse a enviar estudiantes a Roma. De esta forma se continuaría con la formación de futuros obispos. Ibid., 121.
} 
conformado Eulogio Gillow, obispo de Oaxaca; Ignacio Montes de Oca, obispo de San Luis Potosí; Antonio Plancarte, abad de la Basílica de Guadalupe y Jesús Herrera y Piña, del Seminario Conciliar de México. ${ }^{15}$ Gillow y Antonio Plancarte estudiaron en Roma pero no en el Colegio Pío Latinoamericano. Durante las primeras décadas del siglo XX, este grupo, que se educó en Roma, continuaría ejerciendo el poder.

Como obispo de Chiapas (1902-1912), Orozco y Jiménez organizó la extensa diócesis, formó asociaciones católicas y construyó templos. En 1912, el gobierno civil de Chiapas acusó a Orozco y Jiménez de "sublevar a los indios de aquella región" ${ }^{16} \mathrm{y}$ a raíz de ese conflicto recibió el mote de "El chamula". En ese mismo año, como parte de la deferencia especial de Roma hacia los egresados del Colegio Pío Latinoamericano, el papa Pío XI lo designó arzobispo de Guadalajara. El cambio forzado de Orozco y Jiménez del obispado de Chiapas al arzobispado de Guadalajara, debió augurarle a las autoridades de Jalisco un futuro poco tranquilo: frente a ellas se encontraba un novel arzobispo que podía dirigir a su nueva grey por los caminos de la intransigencia. ${ }^{17}$ Tiempo, lugar y condiciones resul-

\footnotetext{
${ }^{15}$ Cecilia Adriana Bautista García, "Hacia la romanización de la Iglesia mexicana”, 123.

${ }^{16}$ Francisco Barbosa Guzmán, Jalisco desde la Revolución: la Iglesia y el gobierno civil, tomo 6, Guadalajara, Gobierno del Estado de Jalisco, Universidad de Guadalajara, 1988, 6: 115. Tiempo después Orozco y Jiménez escribió acerca de su participación en el asunto de los indígenas de Chiapas: "algunos jóvenes, viendo el ascendiente de que yo gozaba ante los indios, me suplicaron que los recomendara para que se dejaran dirigir por ellos y los indios ejercitaran así sus derechos de ciudadanos; pero más tarde aconteció que los habitantes de San Cristóbal de Las Casas quisieron que volvieran allí a residir los poderes que el gobernador Rabasa había trasladado a Tuxtla Gutiérrez, con grande menoscabo y disgusto eterno de la Ciudad Víctima, y los expresados jóvenes los aprovecharon, incorporándolos al Cuerpo de voluntarios que habían organizado para ese conflicto increíble entre Ciudad y Ciudad, más temible que una revolución general, sin que por esto se pueda decir que hubo sublevación de indios, a quienes nada interesaba aquella cuestión: a este abuso agregaron los mencionados políticos el de incomunicarme absolutamente durante todo el tiempo que duró el conflicto, de los pobres indios, para que yo no los disuadiera de prestar su ayuda". Véase Francisco Orozco y Jiménez, Memorándum ¡Acerquémonos a Dios! (Suscrito en San Juan de los Lagos, el 16 de junio de 1918), 13.

${ }^{17}$ En un ensayo reciente, Jean Meyer muestra las semejanzas de las actuaciones al frente de la diócesis de Chiapas entre Orozco y Jiménez y Samuel Ruiz, ex Obispo de Chiapas. Véase Jean Meyer, "Dos Obispos Príncipes, dos hombres una situación", Mi pueblo 131 (2000), 20-23. Sobre el mismo tema reflexiona Fernando M. González en "Sobre las similitudes y diferencias entre los monseñores Francisco Orozco y Jiménez y Samuel Ruiz (polémi-
} 
taron propicios para las ocupaciones del arzobispo, quien fundó seminarios, instaló y reinstaló vicarías, organizó a las damas católicas, y creó el Círculo de Estudios Sociales León XIII. Su controvertida presencia recrudeció los ánimos entre los católicos y el gobierno civil en Jalisco.

Muestra de ello fueron los reiterados destierros que como arzobispo de Guadalajara vivió Orozco y Jiménez, el primero comenzó el viernes 14 de agosto de 1914. Tras las disposiciones anticlericales de los revolucionarios en Jalisco, encabezados por Manuel M. Diéguez, Orozco y Jiménez salió de Guadalajara y se refugió en Chicago, en Nueva York y luego en Roma. Retornó a Guadalajara el 20 de noviembre de 1916. El segundo exilio comenzó el sábado 20 de julio de 1918, también por órdenes de Manuel M. Diéguez, para ese entonces gobernador de Jalisco. En esa oportunidad el arzobispo salió de Guadalajara y radicó en Chicago, Nueva York y Washington. Volvió a Guadalajara el martes 14 octubre de 1919. El tercer distanciamiento de su arquidiócesis fue un autoexilio. A Orozco y Jiménez se le acusó de participar en el movimiento "estradista" en Guadalajara. ${ }^{18}$ Para escapar de sus enemigos, el arzobispo se autoexilió el lunes 2 de junio de 1924: viajó a la ciudad de México, a Roma y después a Chicago. Tornó a Guadalajara en mayo de 1925.

El cuarto exilio principió a finales de julio de 1929. Tras los arreglos entre el gobierno civil y la Iglesia que dieron oficialmente por terminada la guerra cristera, ${ }^{19} \mathrm{el}$ presidente de México, Emilio Portes Gil, ordenó a

ca amistosa con Jean Meyer)", en Matar y morir por Cristo Rey. Aspectos de la cristiada, México, Instituto de Investigaciones Sociales de la UNAM, Plaza y Valdés, 2001, 335-347.

${ }^{18}$ Se llamó movimiento "estradista" al apoyo que el general Enrique Estrada brindó en Jalisco al levantamiento armado de Adolfo de la Huerta en contra del presidente Álvaro Obregón, en diciembre de 1923. Los "estradistas" se posesionaron del gobierno del estado de Jalisco. El entonces gobernador Guadalupe Zuno salió de Guadalajara, mostrando así su adhesión a Obregón (o su recelo ante los "estradistas"; además, el gobierno zunista acusó a Orozco y Jiménez de participar en el levantamiento armado). Alicia Cuevas Miranda, "La política laboral de José Guadalupe Zuno 1923-1926" en idem et al., José Guadalupe Zuno Hernández. Vida, obra y pensamiento, Guadalajara, Universidad de Guadalajara, 1991, 123-139 en especial 134-135. El ministro de Guerra, el general Serrano, declaró en enero de 1924 que la rebelión estradista era considerada como la parte "más peligrosa" de la rebelión delahuertista. Véase "Obregón Preparing for Decisive Blow", The New York Times, 5 de enero de 1924.

${ }^{19}$ Conocida también como "La Cristiada" (1926-1929), consistió en un levantamiento armado de los católicos del occidente mexicano contra el gobierno anticlerical y proagra- 
Orozco y Jiménez que abandonara el país. El arzobispo desterrado salió a El Paso, Texas, para regresar en marzo de 1930. La quinta expatriación la ordenó el presidente Pascual Ortiz Rubio y al arzobispo se le condujo a los Ángeles, California, el domingo 24 enero de 1932. Parte de este exilio lo vivió en Roma. El arzobispo volvió a la capital de Jalisco el domingo 19 de agosto de 1934. Además de estas salidas intempestivas de su patria, Orozco y Jiménez vivió durante dos periodos (1917-1918 y 1926-1929) oculto en pueblos y rancherías alejadas de la ciudad de Guadalajara. El arzobispo dirigió la arquidiócesis, la mayor parte del tiempo, desde la distancia.

En tiempos de la Revolución, la Iglesia en Jalisco limitó, entre 1913 y 1919, su esfera de acción como consecuencia de las medidas restrictivas de los diferentes gobiernos revolucionarios. En contraste, en la década de 1920 -durante el gobierno de Álvaro Obregón en la presidencia de la república (1920-1924)- la Iglesia planeó un "proyecto de reconstrucción que le permitiese retomar su espacio como institución representante de la religión católica".${ }^{20}$ Con este objetivo, los obispos y arzobispos trabajaron en el campo social para desterrar la doctrina del liberalismo y el socialismo. ${ }^{21}$ Los miembros de la jerarquía eclesiástica, en mayor o menor medida, promovieron el programa social de la Iglesia. Dos arzobispos se destacaron en este campo: el de México, José Mora y del Río y el de Guadalajara, Francisco Orozco y Jiménez.

Sin embargo, en 1926 las medidas anticlericales del gobierno de Plutarco Elías Calles (1924-1928), que pretendían regular las prácticas religiosas de los católicos, desataron el descontento de los dirigentes de la Iglesia y de los feligreses de diferentes regiones de México, especialmente del centro occidente. Del desacuerdo entre la Iglesia y el Estado nació la respuesta armada de los católicos. Una vez que se inició la lu-

rista de Plutarco Elías Calles. Ramón Jrade, “La organización de la Iglesia a nivel local y el desafío de los levantamientos cristeros al poder del Estado revolucionario", Estudios del Hombre 1 (1992), 65-80.

${ }^{20}$ Gabriela Aguirre Cristiani, "Iglesia y revolución. Los católicos, el episcopado mexicano y el gobierno de Álvaro Obregón 1920-1924", ponencia presentada en el Congreso Internacional "Dos siglos de revoluciones en México", Morelia, Michoacán, 17 al 20 de septiembre de 2008, 1-27, en especial 10.

${ }^{21}$ Gabriela Aguirre Cristiani, “Iglesia y revolución”, 10. 
cha armada, los obispos se dividieron en dos grupos antagónicos: los que favorecían la intransigencia, que eran los más, y los transigentes que eran minoría.

Francisco Orozco y Jiménez, del ala intransigente, influyó en la vertiente que tomó el conflicto armado en Jalisco, aunque no haya fungido como capellán de los cristeros, como varios historiadores lo han representado. Orozco y Jiménez se opuso a las medidas anticlericales con su presencia pasiva -mientras permaneció escondido en su arquidiócesisy con su autoridad de arzobispo de Guadalajara. A partir de que contravino las órdenes gubernamentales, el 24 de octubre de 1926, fecha en que, a través de un sacerdote jesuita, la Secretaría de Gobernación le pidió que se "presentara espontáneamente" de lo contrario sería "llevado por la fuerza", ${ }^{22}$ las autoridades civiles lo acusaron de ser el cabecilla de los católicos armados. En esta versión se apoyaron las notas, hasta cierto grado sensacionalistas, de la prensa de la época. La figura de Orozco y Jiménez, construida con base en desacatos a las autoridades civiles, se irguió entre los católicos como el símbolo de la resistencia a las medidas anticlericales de los gobiernos locales y nacionales.

\section{DIFERENTES SIGNIFICADOS DE UN FUNERAL}

En el centro, la cama con cabecera de ébano, sostenía la figura inmóvil del arzobispo de Guadalajara, Francisco Orozco y Jiménez. La cabeza, reposada sobre dos cojines, mantenía su frente en alto. Sus manos, tan acostumbradas a formar la señal de la cruz, se ocultaban a la vista, inertes. Vestía sotana oscura, y sobre ésta un manto morado. ${ }^{23} \mathrm{El}$ atuendo cubría brazos y piernas, pero resaltaba lo blanco y delgado de su rostro. La luz se había apagado en sus ojos, es cierto, pero cuatro cirios ardían, a las cuatro esquinas de la cama, e iluminaban toda la recámara. Afuera había oscurecido. El primer mensaje que salió del arzobispado se dirigió

\footnotetext{
${ }^{22}$ Vicente Camberos Vizcaíno, Francisco el Grande: Mons. Francisco Orozco y Jiménez, vol. 2. México, editorial Jus, 1966, 191.

23 "Falleció anoche el Sr. Arzobispo Orozco y Jiménez", El Informador (Guadalajara), 19 de febrero de 1936.
} 
a la Santa Sede en Roma: "Grandísima pena comunico hoy murió Arzobispo Orozco". ${ }^{24}$ Era el 18 de febrero de 1936.

Francisco Orozco y Jiménez murió a consecuencia de la infección que le perjudicó el hígado y le complicó el corazón. Sus funerales duraron cuatro días, del 18 al 21 de febrero de 1936. Iniciaron con la espera de los católicos para ver el cadáver en la casa del arzobispo; después el velorio en el Sagrario Metropolitano; la ceremonia en la catedral y la procesión que recorrió la avenida Alcalde y que condujo el féretro del arzobispo al panteón de Belén. Para entender la simbología detrás del funeral de Francisco Orozco y Jiménez, y comprender el significado de ritual como categoría analítica, retomo los fundamentos del antropólogo David I. Kertzer. Como conducta simbólica, afirma Kertzer, el ritual "es socialmente estandarizado y repetitivo".

La acción ritual tiene una cualidad formal. Sigue secuencias estandarizadas altamente estructuradas y con frecuencia es representada en ciertos lugares y momentos que están dotados en sí con un significado simbólico especial. La acción ritual es repetitiva y, por lo tanto, redundante, pero estos mismos factores sirven como medios importantes para canalizar la emoción, guiar la cognición y organizar a los grupos sociales. ${ }^{25}$

Pese a que por varios siglos no varió en gran medida la forma en que los obispos católicos debían ser enterrados, es evidente que, como lo señala Kertzer, el impacto que se deriva de poner en marcha un ritual, se debe a sus representaciones pasadas: "los recuerdos asociados con aquellas experiencias rituales anteriores dan colorido a la experiencia de una nueva promulgación de los ritos". ${ }^{26}$ Entre más importante es la posición de poder del individuo, "más elaborados y resplandecientes" son

\footnotetext{
${ }^{24}$ Archivo Histórico de la Arquidiócesis de Guadalajara (en adelante, AHAG). Sección gobierno, serie obispos, Francisco Orozco y Jiménez, años 1936-1943, expediente 27, caja 6. Boletín Oficial en que la Sagrada Mitra de Guadalajara, da cuenta al pueblo católico de los telegramas cambiados con la Santa Sede con la ocasión de la gravedad y fallecimiento del Excmo. y Rvmo. Sr. Arzobispo Dr. y Maestro Dn. Francisco Orozco y Jiménez.

${ }^{25}$ David I. Kertzer, Ritual, Politics, and Power, New Haven, Yale University Press, $1988,9$.

${ }^{26} \mathrm{Ibid} ., 12$.
} 
los funerales. En casos de exgobernantes, "su ceremonia se coloca bajo los auspicios del Estado y sufre una transformación. Se convierte en un funeral de Estado: un asunto público en el que el gobierno, los medios y la gente están involucrados".27

En un funeral de Estado se va más allá del rito de paso, puesto que ya pertenece "a la categoría de ceremonias de poder que constituyen una parte integral de cualquier régimen político". Los estudiosos de los funerales, y en particular Ben-Amos, han retomado la teoría de los ritos de paso del antropólogo flamenco Arnold van Gennep. Los ritos de paso, para Van Gennep, son ceremonias que marcan el tránsito de una fase de la vida o la transición de un estatus social a otro. Un periodo tradicional de ritos o rituales marca cada uno de estos cambios. En cada uno de ellos, Van Gennep identificó tres fases: la separación (pérdida por parte de la persona de su estatus anterior), la transición (periodo de transición con rituales específicos) y la reincorporación (readmisión en la sociedad con el nuevo estatus). ${ }^{28}$

"El enfoque retórico", nos dice Avner Ben-Amos, "considera al funeral de Estado como una ceremonia conmemorativa -el aniversario cero de la muerte de un héroe-cuyo objetivo es grabar, en la memoria nacional, el pasado glorioso del difunto y del régimen por el que él luchó" ${ }^{29}$ En el caso de un jerarca de la Iglesia católica como Francisco Orozco y Jiménez, se dan muchos paralelos entre él y la figura de un hombre de Estado. En particular, en lo referente a la experiencia que viven los participantes en la ceremonia, ya como miembros de la procesión o como espectadores, dado el impacto emocional que un rito como el funeral que estudio deja en los participantes del evento, éstos "derivan gran

${ }^{27}$ Avner Ben-Amos, Funerals, Politics, and Memory, 3.

${ }^{28}$ Véase Arnold van Gennep, Los ritos de paso, Madrid, Taurus, 1986.

${ }^{29}$ Avner Ben-Amos, Funerals, Politics, and Memory, 3. Según Ben-Amos, los funerales de Estado en Francia durante la Tercera República "eran, al mismo tiempo, ritos de paso y fiestas cívicas a través de las cuales el régimen celebraba a la vez a sus grandes hombres y sus propios méritos". Para Ben-Amos, los funerales nacionales "ocupaban un lugar exclusivo en las fiestas cívicas del régimen, porque eran los únicos que a la vez eran ritos de paso personales". Avner Ben-Amos, "Les funérailles du maréchal Foch. Le retour de la Grande Guerre", en La mort du roi: essai d'ethnographie politique comparée, coordinado por Jacques Juillard, París, Gallimard, 1999, 231-232; 231-258 
satisfacción" ${ }^{30}$ al participar en éste, de una u otra manera: "La ceremonia, entonces, sirve como mediadora entre diferentes tipos de memorias; la de un individuo solo, la memoria oficial del régimen y la memoria nacional, que intenta moldear" ${ }^{31}$

Para los observadores, el funeral de un "gran hombre", en principio transmite la apariencia de que es un evento totalmente fortuito, sin previa planeación; pero en realidad, como lo muestra Ben-Amos, las tres fases que se dan entre la muerte y el entierro de un individuo: a) la de separación de una posición previa o donde yace el cuerpo del finado; b) la de transición durante la cual el cuerpo se conduce en procesión por las calles; y c) la de incorporación, durante la cual se le traslada a una nueva posición, cuando se sepulta el cuerpo del gran hombre y se une así a sus ancestros, ${ }^{32}$ tienen que ver con etapas previstas. En ellas se siguen requisitos formales que aparentemente no lo son (porque parecen desarrollarse de manera espontánea), pero que están ahí: son una especie de guión de cómo se debe montar esta representación. En otras palabras se trata el funeral como performance: la actuación o ejecución de ciertas etapas siguiendo una normatividad clara y predefinida.

Durante siglos, la Iglesia como institución organizaba los funerales de sus prelados con sumo detalle y cuidaba que las ceremonias influyeran en el ánimo de los fieles. ${ }^{33}$ El funeral del arzobispo de Guadalajara atravesó por tres fases. La de separación de una posición previa en la casa del arzobispo, luego el Sagrario Metropolitano y por último en la aledaña catedral; la de transición en la procesión por la avenida Alcalde (antes San Francisco); y la de incorporación en el panteón de Belén.

\footnotetext{
${ }^{30}$ David I. Kertzer, Ritual, Politics, and Power, 14.

${ }^{31}$ Avner Ben-Amos, Funerals, Politics, and Memory, 6-7.

${ }^{32}$ Avner Ben-Amos, "El centro sagrado del poder: París y los funerales de Estado republicanos", Culturales 6 (2007), 49-74, passim; Avner Ben-Amos y Eyal Ben-Ari, "Resonance and Reverberation: Ritual and Bureaucracy in the State Funerals of the French Third Republic", Theory and Society 24.2 (1995), 163-191, en esp. 169.

33 “Tercer Concilio Provincial Mexicano. Anexo II. Estatutos ordenados por el Santo Concilio Provincial Mexicano en el año del Señor de 1589", en María Pilar Martínez López-Cano, coord., Concilios Provinciales Mexicanos. Época Colonial, México, UNAM, 2004, formato en $\mathrm{CD}, 2$.
} 
El FUNERAL COMO REFLEJO

La etapa de separación de la que nos hablan Van Gennep y Ben-Amos, para el caso que analizo, fue la más prolongada de las tres que constituyen el rito de paso. Estuvo formada por el velorio durante un día y dos noches en la casa particular del arzobispo; una noche en el Sagrario Metropolitano y la ceremonia luctuosa en la catedral. En esta primera fase la noticia de la muerte del personaje marca el inicio de la organización de los funerales. Hay que considerar que la Iglesia como una institución regida por jerarquías bien delineadas, obedece los grados de autoridad. La primera noticia oficial de la muerte del arzobispo se dirigió, respetando esas jerarquías, a la Iglesia en Roma y al papa como máxima autoridad de los católicos. ${ }^{34}$ En segundo lugar, se difundió entre los sacerdotes y los católicos de la arquidiócesis. ${ }^{35}$

El arzobispo reposó en un féretro metálico que a decir de las notas de los periódicos era "una verdadera obra de arte". ${ }^{36}$ Fue entonces cuando la sala de estar de su residencia se convirtió en capilla ardiente. "Una mujer", cuenta una norteamericana que llegó a la residencia arquiepiscopal, "a mi lado lloró y me hizo señas para que le pasara su rosario al guardia". En la primera oportunidad, hombres y mujeres "le ofrecían rosarios o recuerdos a un miembro de la guardia de honor, quien los colocaba en la mano del arzobispo muerto y luego se los regresaba" ${ }^{37}$

${ }^{34}$ Según las reglas que "gobiernan la transmisión de las noticias acerca de la muerte", nos dicen Richard Huntington y Peter Metcalf, importa particularmente el orden en que se difunden las noticias: "la familia inmediata tiene el derecho de conocer [la noticia] dentro de un margen de minutos o de horas, y espera ser informada en persona o por teléfono". Véase Richard Huntington y Peter Metcalf, Celebrations of Death. The Anthropology of Mortuary Ritual, Cambridge, Cambridge University Press, 1985, 198-199.

${ }^{35}$ AHAG. Sección gobierno, serie obispos, Francisco Orozco y Jiménez, años 19361943, expediente 27, caja 6. Boletín de José Garibi Rivera a los sacerdotes y fieles del arzobispado, Guadalajara, 18 de febrero de 1936.

36 "Hoy será inhumado el cadáver de Monseñor Fco. Orozco y Jiménez" , El Informador (Guadalajara), 21 de febrero de 1936.

${ }^{37}$ Bess Adams Garner, Mexico: Notes in the Margin, Boston, Houghton Mifflin Company, 1937, 13. 


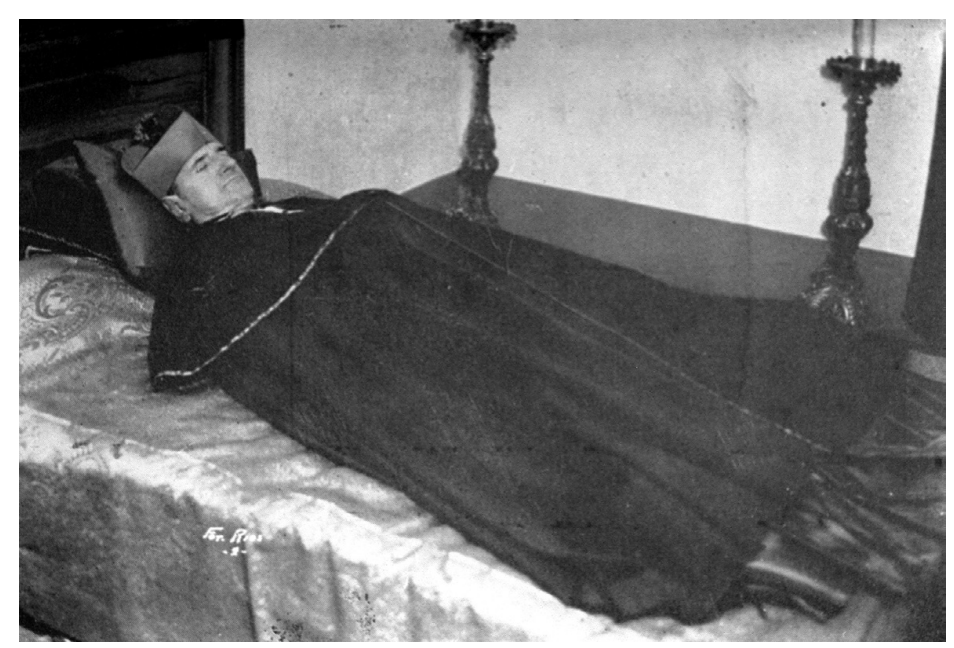

Foto 1. Momentos después de morir. Fuente: Fototeca de El Informador.

Meses después, la gente consideró los rosarios, "benditos esa noche por las manos muertas del arzobispo", como verdaderas reliquias. ${ }^{38}$

La foto 1 muestra al arzobispo ataviado con sus ropas normales, corresponde a la primera noche que fue velado; en la foto 2 aparece embalsamado y revestido con sus ropajes arzobispales, mostrando la dignidad de su cargo. La Iglesia tapatía en la forma de presentar el cadáver, como se aprecia en esta segunda imagen, logró que los católicos de Jalisco percibieran que la persona pública que había construido de sí Orozco y Jiménez se perpetuara en el momento mismo de los funerales. Garibi Rivera en particular, se aseguró que nadie pusiera en duda que Orozco y Jiménez fue el jerarca de más influencia en su arquidiócesis durante el siglo XX.

A la Iglesia en Guadalajara le correspondía homenajear a su arzobispo en su último rito de paso. El cabildo eclesiástico acordó que el cadáver se llevara a la catedral el jueves 20 a las 12 horas del día para velarlo y que un día después, el viernes 21, a las 9 de la mañana, se rea-

\footnotetext{
${ }^{38}$ Ibid., 14.
} 


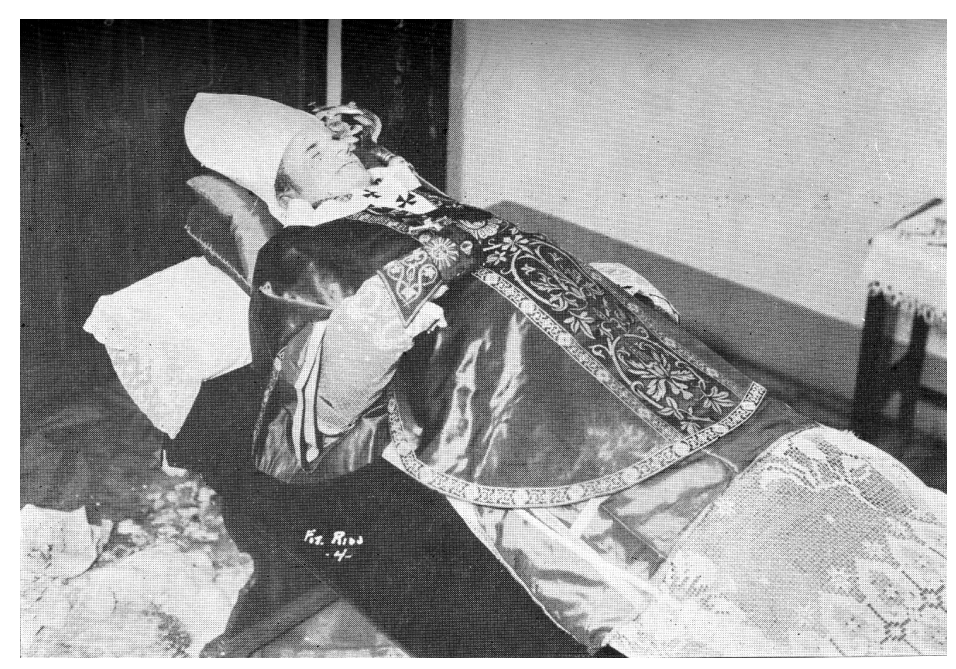

Foto 2. Recubierto con sus insignias arzobispales. Fuente: J. Ruiz Medrano (coord.), Homenaje a la memoria del Excmo. y Reumo. Sr. Dr. y Mtro. D. Francisco Orozco y Jiménez, arzobispo de Guadalajara, Guadalajara, Imprenta Font, 1936.

lizaran los funerales..$^{39}$ Es importante conocer los planes originales del cabildo respecto a la organización del funeral, porque muestran que las disposiciones eclesiásticas se toparon con las órdenes del gobierno civil respecto a los trámites y las modificaron. José Garibi Rivera, podía elegir la opción de ignorar las reglas que imponía el gobierno civil y continuar con la línea dura de su antecesor, o bien cumplir con las disposiciones y transmitir el mensaje de que su gobierno eclesiástico optaría por la conciliación y se sometería a las órdenes de la administración en turno.

Garibi Rivera, eligió la segunda alternativa, y ejecutó las instrucciones que le marcaron las autoridades civiles. Esta conducta de Garibi Rivera era previsible, pues durante la rebelión cristera, se mostró en desacuerdo con la defensa armada de los católicos; más tarde, a principios

\footnotetext{
${ }^{39}$ El cabildo aceptó la propuesta de Garibi Rivera, de que los restos de Orozco y Jiménez se sepultaran en la cripta de la familia Rivera, en el cementerio de Belén. "Libro de Actas Capitulares del V. Cabildo Metropolitano, número XXXI, 484-486", citado en J. Ignacio Dávila Garibi, Apuntes para la historia de la Iglesia en Guadalajara, 5, 524-525.
} 
de la década de 1930, cuando ya era obispo coadjutor de Orozco y Jiménez, actuó con prudencia respecto a la reglamentación del culto en Jalisco, ${ }_{10}^{40}$ para evitar enfrentamientos con las autoridades civiles.

El funeral de Orozco y Jiménez, cual espejo, reflejó la conflictiva relación entre la Iglesia y el Estado: no se realizó el velorio en la catedral, como estaba previsto, ante las complicaciones que surgieron para obtener el permiso correspondiente. En consecuencia, el velorio se efectuó en el Sagrario Metropolitano. El entonces presidente municipal de Guadalajara Florencio Topete, negó el permiso del traslado del cadáver a catedral, pese a que lo había autorizado el secretario del gobierno estatal. ${ }^{41}$ Topete prefirió que el secretario de Gobernación, en la capital de la República, aprobara esa medida. Los trámites para el funeral del arzobispo cobraron dimensión nacional en el momento en que las autoridades locales transfirieron el asunto a la Secretaría de Gobernación, y pusieron en manos de los mandos nacionales la responsabilidad de lo que -si algo salía mal- podría convertirse en el foco de un nuevo conflicto entre católicos y autoridades civiles.

Hay que considerar que el gobernador de Jalisco, Everardo Topete (1935-1939), al igual que su antecesor Sebastián Allende (1932-1935), ${ }^{42}$ implementó medidas anticlericales, sumadas a la polémica por implantar la educación socialista y el conflicto universitario, aspectos que enrarecieron el clima de represión en la entidad. En marzo de 1935, mientras se desataba el conflicto universitario, en un mitin político se enfrentaron miembros de la Federación de Estudiantes de Jalisco con otros grupos antagónicos; el saldo fue de varios muertos y heridos. El gobierno culpó al clero de estar involucrado en el suceso, así como a "estudiantes reac-

\footnotetext{
${ }^{40}$ Patricia Valles, "José Garibi Rivera: primer cardenal mexicano", en A Dios lo que es de Dios, coordinado por Carlos Martínez Assad, 267-285, México, Aguilar, 1994, 272.

${ }^{41}$ AHAG. Sección gobierno, serie obispos, Francisco Orozco y Jiménez, años de 19361943, expediente 27, caja 6. Carta de Miguel Guevara, secretario del gobierno de Jalisco al presidente municipal Florencio Topete. Guadalajara, 19 de febrero de 1936.

${ }^{42}$ En 1934, contendieron por la gubernatura el candidato cardenista Silvano Barba González y el candidato callista que apoyaba el grupo del gobernador Sebastián Allende, Everardo Topete. Topete, el nuevo gobernador de Jalisco, recibió un gobierno "consolidado" gracias a la gestión de Allende, quien sometió "al clero y a un buen número de caciques". Véase Alma Dorantes González, "El conflicto universitario en Guadalajara", 19331937", Tesis de maestría, Universidad de Guadalajara, 1993, 133.
} 
cionarios y a elementos fanáticos" ${ }^{43}$ A raíz de ese hecho, el gobernador Everardo Topete ordenó que el ejército disolviera las marchas no autorizadas. Los militares "patrullaron durante varios días la ciudad con objeto de no permitir la reunión de más de cinco personas en las calles y plazas". ${ }^{44}$

De autorizarse el traslado del cuerpo a la catedral, quedaba implícito que se consentiría que los católicos acompañaran al arzobispo en su último recorrido por el centro neurálgico de Guadalajara. El tiempo en el que el arzobispo murió, no era el más propicio para que, con toda libertad, la Iglesia organizara los funerales del prelado al igual que en otras épocas preparaba los actos públicos de culto. La guerra cristera, en la que Orozco y Jiménez tuvo un papel protagónico, era todavía un tema vigente tanto para los católicos como para las autoridades civiles. Pese al clima de represión y a la presencia meses antes de militares por las calles de la ciudad, los católicos tapatíos se apostaron para participar en los diferentes actos del funeral de su arzobispo.

Lejos de ser un evento improvisado, cuando la preparación de un funeral toma varios días, a los organizadores se les permite imbuir al evento con un simbolismo que escapa a primera vista a los mismos participantes. No sólo los funerales de un "gran hombre" como el arzobispo de Guadalajara servirían para congregar a los católicos jaliscienses, sino que los organizadores, encabezados por Garibi Rivera, fraguaron su movilización para resaltar los valores de unidad y obediencia que la misma Iglesia en Jalisco intentó infructuosamente de implantar incluso durante los últimos años de vida de Orozco y Jiménez.

Por ejemplo, el convulsivo año de 1935 fue difícil para los habitantes de Jalisco: "en la ciudad, frente al impulso oficial a la educación socialista, las clases medias enarbolaron la educación laica, la autonomía universitaria y la libertad de cátedra como límites a la expansión del Estado posrevolucionario".$^{45} \mathrm{El} 18$ de octubre de ese año fuerzas federales aprehendieron a 31 sacerdotes por considerarlos sospechosos de planear una rebelión. A los clérigos se les encarceló. Tras las averiguaciones, el juez

\footnotetext{
${ }^{43}$ Alma Dorantes González, "El conflicto universitario en Guadalajara", 270.

${ }^{44}$ Ibid.

${ }^{45}$ Ibid., 88.
} 
segundo de Distrito les levantó el cargo, pero enseguida les dictó formal prisión por violar la ley de culto vigente. ${ }^{46}$

La prensa ventiló que Orozco y Jiménez era el cabecilla de la rebelión que se fraguaba en Jalisco. Tal vez atendiendo a esa sospecha, el 19 de octubre de 1935, las fuerzas federales catearon la casa del arzobispo en San Pedro, Tlaquepaque, y el Santuario de la Soledad en busca de su persona ${ }^{47}$ José Garibi Rivera, en carta abierta, fechada el 1 de noviembre de 1935 y publicada en el periódico El Informador, pidió a Lázaro Cárdenas garantías para los sacerdotes y para el arzobispo. ${ }^{48} \mathrm{La}$ organización de los funerales de Orozco y Jiménez reflejó las tensas relaciones en el pasado inmediato entre la Iglesia y el Estado, las autoridades civiles recelaban de las eclesiásticas en atención a su larga tradición de oponerse al régimen.

\section{EL FUNERAL Y EL ESPACIO PÚBLICO}

Todos los actos del funeral del arzobispo tuvieron lugar en el "centro sagrado" de la ciudad de Guadalajara. Es decir, después de muerto, el arzobispo no salió de ese espacio significativo para la Iglesia y los católicos, como para el gobierno civil. En el centro además de la catedral, se encontraban las sedes del poder estatal y municipal. El centro de la ciudad, ya lo dijo Ben-Amos, guarda los valores más viejos; ahí la arquitectura se transforma con lentitud. Los edificios y las casas forman un conjunto que enmarca celebraciones tales como festivales cívicos y funerales significativos. En la década de los treinta, la ciudad de Guadalajara modificó sus espacios. Con la injerencia del "Estado y de las clases sociales", resultó en "una ciudad con espacios mucho más diferenciados en cuanto a sus funciones"; así, las familias de la clase alta se establecieron en "colonias ubicadas en el poniente y el norte con la subsecuente especialización del centro como zona comercial y de oficinas. Las colonias de las clases medias crecieron hacia el oriente, el norte y el

\footnotetext{
${ }^{46}$ AGN. Grupo documental Lázaro Cárdenas del Río, volumen 914, expediente 5473/86. Carta abierta de José Garibi Rivera a Lázaro Cárdenas, Guadalajara, 1 de noviembre de 1935 .

${ }^{47} \mathrm{Ibid}$.

48 "Carta abierta", El Informador (Guadalajara), 10 de noviembre de 1935.
} 
noreste; por su parte, las clases populares saturaron los barrios tradicionales" ${ }^{49}$

La catedral de Guadalajara fue, por definición, el medio en el que Orozco y Jiménez se desenvolvió durante los 23 años que duró su arzobispado. Pero también lo fueron el Sagrario Metropolitano y el Santuario de Guadalupe. Esos edificios estaban revestidos de valor. En principio la catedral era el símbolo para los católicos de la arquidiócesis; y el medio o el espacio en el que el arzobispo se revestía del poder que le confería la Iglesia, como el sucesor de los apóstoles que era. ${ }^{50}$ Por otra parte, el Sagrario Metropolitano, ubicado en el costado sur de la catedral, era una especie de prolongación de esta última. Al Santuario de Guadalupe lo separaban varias cuadras de la catedral; pero uno de sus costados daba a la entonces calle de San Francisco la misma en que se situaban los dos recintos antes mencionados. La zona del Santuario era una zona popular, y para Orozco y Jiménez guardaba un doble significado: el arzobispo era ferviente seguidor de la Virgen de Guadalupe, como "símbolo de todos los católicos mexicanos", ${ }^{51}$ y el barrio lo habitaban las clases populares.

Estas construcciones quedaron, en los días del funeral de Orozco y Jiménez, conectadas entre sí. Después de que se veló durante dos días el cadáver del arzobispo en su casa, a las 16 horas del jueves 20 de febrero se formó una procesión que recorrió unas cuantas cuadras hasta llegar al Sagrario Metropolitano. De ahí se trasladó el cadáver a la catedral, el viernes 21 a las 9 horas. En estos dos actos, los fieles usaron el espacio público para acompañar y manifestar gratitud al arzobispo muerto, pero también para desafiar simbólicamente a las autoridades gubernamentales, pues tomaron las calles inmediatas cuando se volvió imposible entrar a la catedral, apropiándose el espacio público más allá de los edificios dedicados al culto.

Una nueva etapa se iniciaba para la Iglesia tapatía en relación con el Estado. Seguramente informadas las autoridades nacionales de la mul-

\footnotetext{
${ }^{49}$ Alma Dorantes González, "El conflicto universitario en Guadalajara", 83.

${ }^{50}$ Adriano Cance y Miguel de Arquer, El Código de derecho canónico, 2 vols., Barcelona, Litúrgica Española, 1933, 1: 220.

51 "Our Lady of Guadalupe", http: / / en.wikipedia.org/wiki/Our_Lady_of_Guadalupe (Fecha de acceso: 2 de mayo de 2009).
} 
titud que se apostaba frente a la casa donde Orozco y Jiménez yacía, decidieron otorgar "un permiso" que el mismo pueblo ya había tomado por su cuenta, de salir a la calle.

\section{El FUNERAL COMO ESPECTÁCULO}

El espectáculo que la Iglesia preparó se resumió en el funeral. Dicho espectáculo se dio en dos grandes actos y tuvo lugar específicamente dentro de los dos templos mencionados, es decir en los recintos de culto; nunca en el espacio exterior. Una vez que el cadáver de Orozco y Jiménez proveniente de su casa y acompañado del nuevo arzobispo traspasó la puerta del Sagrario, ésta se cerró y se impidió la entrada a los fieles. La puerta se abrió sólo hasta que el Sagrario se transformó en un escenario que prestaba su boato al ataúd del arzobispo, que se encontraba en el centro sobre una gran mesa cubierta con paños negros, rodeada por seis cirios. El efecto visual lo complementaron los organizadores con el auditivo, cuando se aseguraron que al entrar los fieles escucharan el canto de los maitines. El arreglo del templo, según testigos oculares, transmitía un "tono de tristeza solemne". ${ }^{22}$ Después de esa apertura dramática y de que los fieles entraran al Sagrario para observar el cuerpo del arzobispo, las guardias de honor privilegiaron en orden de preeminencia a la jerarquía eclesiástica, después de ésta los feligreses montaron guardias. Se calculó que "no menos de cuarenta mil personas desfilaron ante el féretro". ${ }^{53} \mathrm{Si}$ se considera que la población de la ciudad de Guadalajara en 1930 era de 184,826 habitantes ${ }^{54}$ esto significa que casi 25 por ciento de la población de la ciudad participó en el funeral. ${ }^{55}$

52 “Hoy será inhumado el cadáver de Monseñor Fco. Orozco y Jiménez”, El Informador (Guadalajara), 21 de febrero de 1936.

${ }^{53}$ Rafael Rafael Regalado, “Postrer Homenaje”, en Homenaje a la memoria del Excmo. y Revmo. Sr. Dr. Mtro. Francisco Orozco y Jiménez, arzobispo de Guadalajara, coordinado por J. Ruiz Medrano, 42-47, Guadalajara, Imprenta Font, 1936, 45.

${ }^{54}$ Alma Dorantes González, "El conflicto universitario en Guadalajara", 79.

${ }^{55} \mathrm{Sin}$ embargo, también existieron personas que no comulgaron con la política religiosa de Orozco y Jiménez, por ejemplo la señora María Concepción Remus de Matute, a quien el arzobispo había excomulgado. Remus de Matute catalogó de "borregos" a los 
El segundo acto del espectáculo del funeral, y el principal, fue en la catedral. El centro de la Iglesia tapatía-la catedral-era al mismo tiempo que el núcleo de su reino temporal, un espacio sacro; es decir, "un lugar en donde se enfocan los valores sagrados de una comunidad y se vuelven tangibles a través de un conjunto de símbolos y rituales, y donde se comunica la sociedad con estos valores sagrados" ${ }^{56}$ Una vez que el cadáver de Orozco y Jiménez entró a la catedral el viernes 21 a las 9:00 horas, de inmediato lo colocaron en un catafalco que había servido para el mismo propósito en los funerales de otros obispos. La organización del evento y su magistral sincronización de súbito se sintieron. Los severos cortinajes negros "en todas las columnas y uno mayor en la cúpula, sobre el altar", ${ }^{57}$ la música -la "partitura fúnebre del abate Lorenzo Perossi" - ejecutada por la filarmónica "Santa Cecilia" y dirigida por el presbítero Manuel Aréchiga; ${ }^{58}$ y la oración fúnebre que pronunció Manuel Fulcheri y Pietra Santa, obispo de Zamora, en la que exaltó las "cualidades que adornaron la vida del [quinto] arzobispo" 59 de Guadalajara, contribuyeron a que los numerosos asistentes, colocados de acuerdo a su jerarquía eclesiástica y social, se creyeran ante una representación teatral, tal como la concibe el antropólogo Clifford Geertz.

Geertz señala que, en Bali, los funerales de los reyes conformaban un espectáculo para el pueblo. El acto principal del funeral era la incineración. Ese suceso congregaba a la multitud, que iba vestida de fiesta. El lugar de la cremación estaba dispuesto para el espectáculo. Los asistentes ocupaban un lugar privilegiado en el que observaban cómodamente el evento. Había una torre de 11 pisos; en el sitio superior, se colocaba el cuerpo del rajá. La torre decorada, y el ataúd en forma de animal, eran elementos que contribuían a la espectacularidad del evento. ${ }^{60}$ En el caso

católicos que siguieron de cerca los diferentes actos del funeral del arzobispo. Véase, Bess Adams Garner, Mexico: Notes in the Margin, 15.

${ }^{56}$ Avner Ben-Amos, "The Sacred Center of Power", 28.

${ }^{57}$ J. Ignacio Dávila Garibi, Apuntes para la historia de la Iglesia en Guadalajara, 5, 229.

58 "Los funerales del Sr. Arzobispo D. Francisco Orozco y Jiménez revistieron gran solemnidad", El Informador (Guadalajara), 22 de febrero de 1936.

${ }^{59} \mathrm{Ibid}$.

${ }^{60}$ Clifford Geertz, "La afirmación política: espectáculo y ceremonia”, en Idem, Negara. El estado-teatro en el Bali del siglo XIX, Barcelona, Paidós, 1999, 177-215, passim. 
de la catedral de Guadalajara, el catafalco con el ataúd de Orozco y Jiménez era el centro del espectáculo.

Los estudiosos de los funerales, en particular Ben-Amos, señalan que la cercanía en relación con el féretro, revela el grado de importancia social o política de los asistentes. Las guardias de honor fueron un claro ejemplo de la dimensión vertical y horizontal que conforma a la Iglesia. Según De la Torre, la institución católica está formada por la Ecclesia que se refiere a la "estructura jerárquica" y al "funcionamiento vertical" que emana del Vaticano para las Iglesias locales. Nostra alude a la "comunidad de cristianos" que "forman parte de la Iglesia"; ésta sería la dimensión horizontal. Sin embargo, ambas dimensiones, aunque separadas, interactúan entre sí. ${ }^{61}$

De la Torre aplica lo anterior para un periodo reciente de la Iglesia en Guadalajara en el que analiza "el catolicismo desde la perspectiva de los laicos"; en mi caso lo retomo para destacar esas dos dimensiones -la de la jerarquía y la de los fieles- de la Iglesia como institución. Dimensiones que se reflejaron en los funerales del arzobispo, especialmente en las guardias que se montaron en el Sagrario y en la procesión del funeral. Por ejemplo, en primer término se ubicaban los miembros del cabildo metropolitano, vestidos con su traje ordinario; ${ }^{62}$ al pie del catafalco estaban los sacerdotes de las parroquias, las órdenes religiosa ${ }^{63}$ y sólo conforme pasaban las horas, hicieron guardia muchos de los habitantes de la ciudad. ${ }^{64}$

Los deudos del fallecido, o las autoridades a quienes por jerarquía les corresponde representar el papel de orquestador de los funerales, están obligados por las normas no escritas de las ceremonias fúnebres -pero observadas desde hace tiempo por sociólogos y antropólogos ${ }^{65}$-a no separar-

\footnotetext{
${ }^{61}$ Renée de la Torre, La Ecclesia Nostra, El catolicismo desde la perspectiva de los laicos: el caso de Guadalajara, México, Fondo de Cultura Económica, CIESAS, 2006, 15.

${ }_{62}$ "Libro de Actas Capitulares del V. Cabildo Metropolitano, número XXXI, 484-486", citado en J. Ignacio Dávila Garibi, Apuntes para la historia de la Iglesia en Guadalajara, 5, 524.

${ }^{63}$ AHAG. Sección gobierno, serie obispos, Francisco Orozco y Jiménez, años 19361943, expediente 27, caja 6. Invitación de Narciso Aviña Ruiz a Fray Bernardino Madrueño. Guadalajara, 19 de febrero de 1936.

${ }^{64}$ Rafael Regalado, "Postrer Homenaje", 44.

${ }^{65}$ Véase Erving Goffman, La presentación de la persona en la vida cotidiana, Buenos Aires, Amorrortu, 2004, 47.
} 


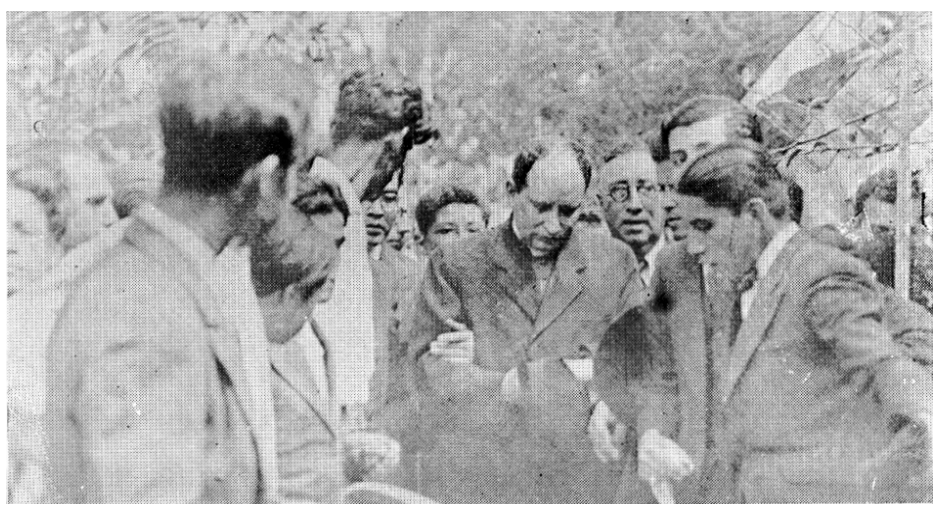

Foto 3. Cabizbajo, José Garibi Rivera acompaña los restos de Francisco Orozco y Jiménez. Fuente: J. Ruiz Medrano (coord.), Homenaje a la memoria del Excmo. y Revmo. Sr. Dr. y Mtro. D. Francisco Orozco y Jiménez, arzobispo de Guadalajara, Guadalajara, Imprenta Font, 1936.

se del cadáver y mostrar tristeza. Por extraño que parezca, los dolientes presentan una cara de congoja por la pérdida reciente del ser querido, porque entienden que eso es lo que se espera de ellos. Las fotografías que sobreviven de JoséGaribi Rivera bajo estas circunstancias lo muestran en una actitud triste, dolida. Pero como lo observa Durkheim: quizá no porque se sintiera de esa manera, sino porque entendía perfectamente que ese era el papel que debía desempeñar. La tristeza de los deudos del difunto "surge no porque se esté triste, sino porque se está obligado a hacerlo": porque esa es la costumbre del grupo al que pertenece. ${ }^{66}$ La evidente pesadumbre de las autoridades eclesiásticas formó parte sustancial del espectáculo del funeral, especialmente dentro del Sagrario Metropolitano y de catedral.

EL FUNERAL A TRAVÉS DE LA ESTRUCTURA Y EL COMMUNITAS

La segunda fase del funeral correspondió a la etapa de transición y consistió en la procesión del funeral por la avenida Alcalde. Esta etapa se

${ }^{66}$ Émile Durkheim, Las formas elementales de la vida religiosa, México, Ediciones Coyoacán, 1995, 370. 
inició en el momento mismo en que terminó la celebración religiosa y el féretro salió de la catedral. Analizo la procesión del funeral a la manera metafórica de una peregrinación a través de la noción de estructura y communitas que emplea Victor Turner. Para Turner estructura y communitas se presentan "generalmente en oposición". Según Turner, "el communitas aparece cuando la estructura no lo hace". Por communitas Turner entiende esa fase en la que se da un "sentimiento de camaradería en las personae liminales". En contraste, explica que "la estructura social se refiere a un arreglo de posiciones o estatus". El communitas surge en la fase de liminalidad. Es decir, cuando los individuos son ellos mismos.

Turner "argumentó que communitas y estructura también se refieren a dos modalidades de la sociedad. Concebía a la sociedad como que involucraba un proceso dialéctico entre communitas, la comunidad indiferenciada de individuos iguales y la estructura, el sistema diferenciado y con frecuencia jerárquico de posiciones [o puestos] sociales" ${ }^{67}$ Turner aplicó los conceptos anteriores al análisis de peregrinaciones, en las que demostró que en éstas se borran las diferencias sociales. Sin embargo, Renée de la Torre encontró que dentro de las procesiones también pueden darse simultáneamente la estructura y el communitas ${ }^{68}$ Las peregrinaciones son un espacio en el que los peregrinos participan en "el sentido de identidad compartida", pero "idealizado en el sentimiento de communitas" ${ }^{69}$ De la Torre analizó el caso de la romería de la Virgen de Zapopan que tiene lugar cada 12 de octubre en la zona metropolitana de Guadalajara y demuestra que el carácter de las peregrinaciones es "ambiguo", y en ellas no necesariamente se trastocan o desaparecen "las representaciones de autoridad y jerarquía".$^{70}$

Al estudiar la peregrinación de la Virgen de Zapopan bajo los postulados de Turner, De la Torre proporciona un ejemplo cercano a la procesión funeraria. Un ejemplo en el cual la teoría de este antropólogo puede

\footnotetext{
${ }^{67}$ Mathieu Deflem, “Ritual, Anti-Structure, and Religion: A Discussion of Victor Turner's Processual Symbolic Analysis" http:/ / www.cas.sc.edu/ socy / fac (fecha de acceso: 30 de abril de 2009).

${ }^{68}$ Renée de la Torre, "La eclesialidad representada en la romería de la Virgen de Zapopan", en Ciencias Religiosas 4, 2001, 39-46.

${ }^{69}$ Ibid., 40 .

${ }^{70} \mathrm{Ibid}$.
} 
entenderse en un caso concreto. La autora señala que la romería de Zapopan está lejos de adecuarse a la idea de "un lugar idóneo de communitas", en cambio se observa que "se da una pugna por la definición de las prácticas rituales ligadas al catolicismo, en donde a la vez está presente la estructura y el communitas". ${ }^{71}$

En el caso del funeral del arzobispo Orozco y Jiménez se encontró la estructura y el communitas entre varios elementos a los que se refiere De la Torre para el caso de la romería, quien afirma que "las peregrinaciones dramatizan tanto una forma de estar juntos, idealizado en el sentimiento de communitas, como la realidad fáctica del orden social, cimentado en la estructura, que impone jerarquías, normas y comportamientos institucionalizados por la ortodoxia católica". ${ }^{22}$ Las peregrinaciones católicas reúnen tres características: "integrar, resistir y renovar", ${ }^{73}$ atendiendo esas particularidades "en ellas se dramatizan en un mismo escenario espacio-temporal" dos aspectos: las normas que la Iglesia como institución jerárquica dispone para "estructurar los modos de acceso a lo sagrado" y las "prácticas espontáneas de los creyentes que manifiestan la resistencia, la reinvención y el dinamismo simbólico". ${ }^{74}$

Las mujeres fueron un sector de la población al que, durante los 23 años del arzobispado de Orozco y Jiménez, la política católica se dirigió como formadoras en el hogar. Numerosas de ellas permanecieron muy cercanas a la puerta de catedral cuando la entrada a las exequias se volvió inaccesible (se observan en las fotografías con las cabezas cubiertas con pañoletas), se deduce que las mujeres fueron las primeras que vislumbraron el ataúd del arzobispo. Enseguida se formó la procesión, compuesta por todas las clases sociales, según reporte de los periódicos de la época. Si tenemos en cuenta que en la ceremonia dentro de la catedral se marcaron las jerarquías tanto eclesiásticas como sociales, cuando el féretro salió de ese recinto, la procesión que formaron los fieles borró esas diferencias de clase entre ellos. Durante la procesión las personas caminaron con los brazos entrelazados, según se aprecia en la foto 4 y se reporta en las notas de periódico.

\footnotetext{
${ }^{71}$ Ibid., 46.

${ }^{72}$ Ibid., 40.

${ }^{73}$ Ibid.

${ }^{74} \mathrm{Ibid}$.
} 


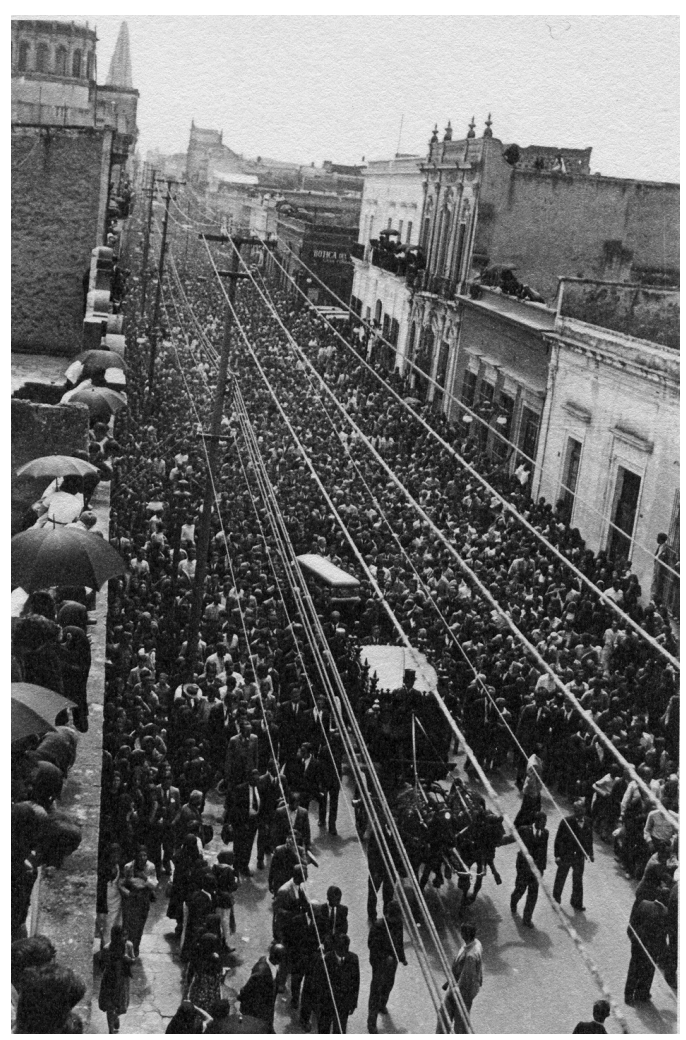

Foto 4. La procesión. Fuente: H2-047a, Centro Documental de las Artes de Jalisco, Dirección de Investigaciones Estéticas, Dirección General de Patrimonio Cultural, Secretaría de Cultura del Gobierno del Estado de Jalisco.

La procesión del funeral, recordemos, se efectuó el viernes 21 de febrero de 1936. Ese luctuoso día, la gente abandonó sus ocupaciones habituales para asistir al acto. De la Torre señala que "durante la peregrinación, se suspenden temporalmente las estructuras del orden, de la normatividad y de la normalidad de la organización social. Por ejemplo, se interrumpe con el trabajo para liberar el tiempo; se invierte la obligatoriedad de las actividades diarias por una actividad voluntaria que es sumarse a la peregrinación: se dejan los lugares de residencia para des- 
plazarse a un santuario, se abandona la vida profana para lograr una experiencia (individual y colectiva) sagrada". ${ }^{75}$ Eso fue lo que ocurrió en la procesión, la gente de la ciudad y de puntos circunvecinos: dejaron sus ocupaciones habituales y sus lugares de residencia para sumarse al funeral y, más particularmente, a la procesión.

El cortejo fúnebre se encaminó por la amplia avenida Alcalde (antes de San Francisco) una de las arterias vitales de la ciudad, en dirección norte, rumbo al legendario panteón de Belén (véase mapa de la procesión). ${ }^{76}$ Para que esa procesión avanzara, se formó una valla humana desde catedral hasta el cementerio. A esa larga columna se integraron más de 300 vehículos que también enfilaron hacia el panteón de Belén. "Sin hipérbole estaba la mitad de los habitantes locales". ${ }^{77}$ En las plazas, en las aceras de la calle, en las azoteas, en los balcones y ventanas de las casas, la gente observó el funeral.

Otras personas siguieron el cortejo por callejuelas adyacentes como la de Pedro Loza "lo mismo que por las demás calles que convergen al panteón de Belén, hasta situarse frente a éste, ocupando algunas cuadras a la redonda en el lado poniente del mismo" ${ }^{78}$ El cortejo recorrió nueve cuadras en línea recta de la avenida Alcalde hasta llegar a la esquina con Juan Álvarez, lugar donde se ubicaba un barrio popular habitado por obreros y se alzaba el Santuario de Guadalupe, un edificio simbólico para Orozco y Jiménez: ahí se le recibió cuando se le nombró arzobispo de Guadalajara, y allí regresaría en varias ocasiones para encabezar los desfiles de los católicos que, con o sin permiso de las autoridades, iniciaban y terminaban en ese recinto. El que el cortejo enfilara hasta el Santuario en vez de ir directamente a la calle de Belén en donde

\footnotetext{
${ }^{75}$ Renée de la Torre, "La eclesialidad representada en la romería", 40.

${ }^{76}$ El panteón de Santa Paula o de Belén se construyó en 1848, sin embargo su erección estaba planeada desde 1787, fecha en que se inició el proyecto del Hospital de San Miguel, que contemplaba contar con un cementerio anexo. El panteón de Belén se edificó con el apoyo del obispo Diego Aranda y Carpinteiro; Manuel Gómez Ibarra fue el arquitecto encargado de levantarlo. Véase Ramiro Villaseñor y Villaseñor, Epigrafía del panteón de Belén, Guadalajara, Gobierno del Estado de Jalisco, 1985, 11.

77 "Funerales de Mons. Orozco y Jiménez. El arzobispo de Zamora hizo el elogio al desaparecido. Las honras fúnebres", El Universal (ciudad de México), 22 de febrero de 1936.

78 "Los funerales del Sr. Arzobispo D. Francisco Orozco y Jiménez, revistieron gran solemnidad", El Informador (Guadalajara), 22 de febrero de 1936.
} 
Procesión funeral del arzobispo de Guadalajara Francisco Orozco y Jiménez (1936).
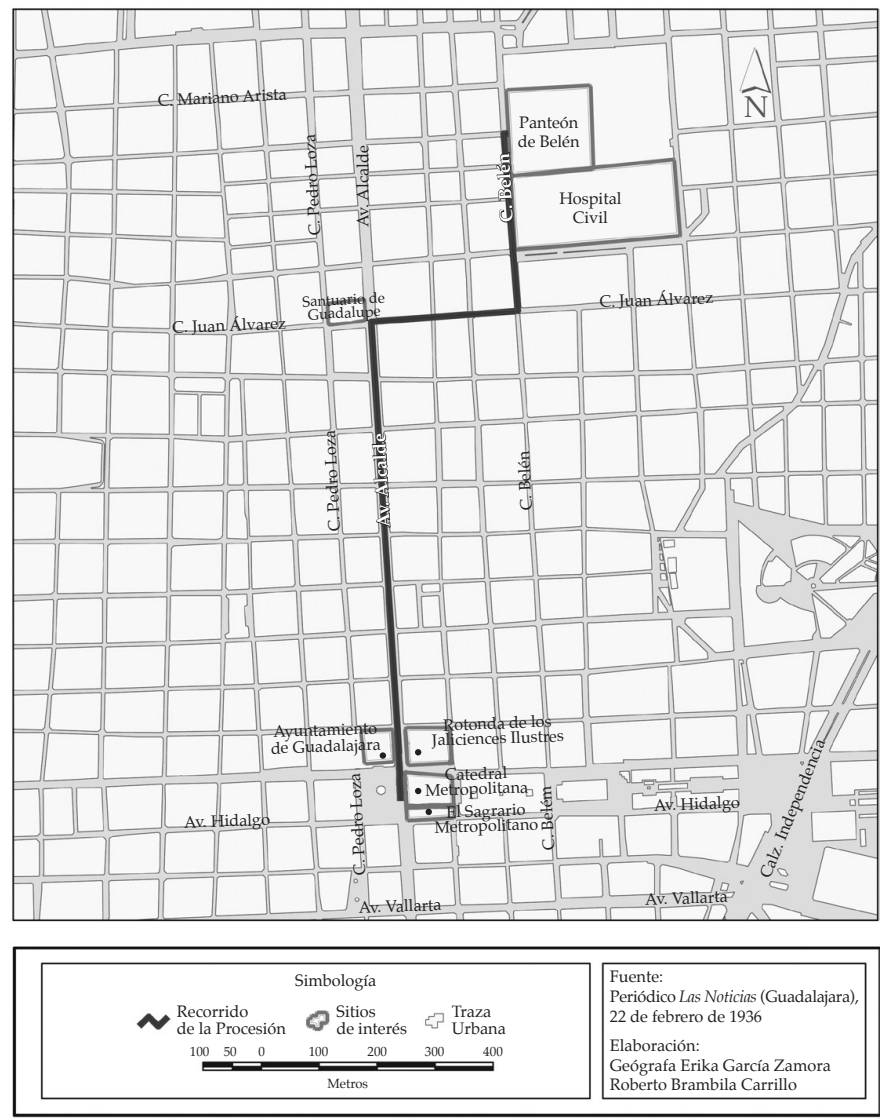

se ubicaba el panteón, no fue fortuito: permitió a la gente pobre (la misma que tradicionalmente había seguido de cerca al arzobispo) identificarse también con el difunto.

Una vez que llegó a la esquina del santuario, el cortejo bajó tres cuadras por la calle de Juan Álvarez hasta alcanzar el entrecruce con la de Belén. De ahí continuó dos cuadras más para llegar al panteón. La procesión terminó con el ingreso al panteón de Belén. El gobierno civil ma- 
nifestó su autoridad a través de la presencia de la "policía de tráfico" y de los "servicios de vigilancia y auxilio". Los fieles que no pudieron entrar aguardarían afuera hasta que se sepultó el cuerpo del arzobispo.

La tercera fase del funeral, correspondió a la reintegración, es decir al momento en que el cuerpo es enterrado, y se une a sus ancestros. José Garibi Rivera optó por inhumar a Orozco y Jiménez en la tumba de su familia. El joven Antonio Llerenas, integrante de la antigua unión de sindicatos de obreros católicos -asociación que albergó más de treinta sindicatos católicos, los cuales empezaron a formarse alrededor de 1919 a instancias del arzobispo Orozco y Jiménez, con el apoyo de los sacerdotes de las parroquias- pronunció un discurso antes de que el féretro entrara a la cripta. ${ }^{79}$ Llerenas "expresó [al arzobispo] la gratitud y el cariño de los trabajadores" ${ }^{80}$ Según Ben-Amos uno de los secretos de la longevidad de la Iglesia universal es que ha sabido movilizar el apoyo de los creyentes al atraer a las masas utilizando su propio lenguaje. ${ }^{81}$

Al menos simbólicamente Garibi Rivera asumió la muerte de Orozco y Jiménez no sólo como su sucesor, sino como "un hijo" que vio morir a su padre. Así, el nuevo arzobispo se apoderó en el último instante del cuerpo de Orozco y Jiménez, a quien en los días anteriores e inmediatamente posteriores a su fallecimiento, se refirió como a un progenitor. Así acentuaba, el sucesor, los lazos que lo unían con el gran hombre de la Iglesia.

En la procesión del funeral se dio la noción de communitas entre los fieles de la arquidiócesis, ante la pérdida de uno de sus miembros. Al caminar hombro con hombro y con los brazos entrelazados, los feligreses se hermanaron a través del dolor que les provocó la muerte de su líder religioso. La noción de estructura se observó cuando el féretro apareció acompañado por la jerarquía eclesiástica. El orden en que marchó el cortejo (según se observa en las fotografías) dio preeminencia a la carroza, tirada por dos caballos y un cochero vestido de gala; después venía el ataúd en hombros de los sacerdotes, quienes se turnaron hasta llegar al

\footnotetext{
${ }^{79}$ Sin autor, "A la memoria del amado padre desaparecido el Excmo. Y Rvdmo. Sr. Dr. y Maestro Don Francisco Orozco y Jiménez" . Labor 28 (1936), 4-66, 50. También Vicente Camberos Vizcaíno, Francisco el Grande, 2, 480.

${ }^{80} \mathrm{~J}$. Ignacio Dávila Garibi, Apuntes para la Historia de la Iglesia en Guadalajara, 5, 230.

${ }^{81}$ Avner Ben-Amos, "Patriotism and Popular Culture in the State Funerals of the French Third Republic", History of European Ideas 16 (1993), 4-6, 459-465, 463.
} 
panteón de Belén. Garibi Rivera presidió el cortejo. Enseguida estaban los miembros del cabildo eclesiástico, la curia y demás sacerdotes de la arquidiócesis y de otras sedes. ${ }^{82}$ Ya mencioné que al final caminaba el público general, que también se distribuyó a los costados de la procesión: los feligreses que participaron en la marcha, formaron una especie de cuadrado en cuyo centro estaba el ataúd que "ondeaba como una bandera". 83

En esta procesión, el recién estrenado arzobispo de Guadalajara, José Garibi Rivera, estuvo expuesto a las miradas de decenas de miles católicos que observaron en silencio la procesión desde la distancia. Garibi Rivera, a quien los veteranos cristeros consideraban un traidor a su causa, ahora quedaba frente a ellos y frente al resto de los católicos como el heredero legítimo de Francisco Orozco y Jiménez, de quien se creía había emanado buena parte del impulso de la insurrección cristera en Jalisco y el colindante estado de Colima.

\section{CONCLUSIONES}

Las autoridades eclesiásticas tapatías planificaron con sumo cuidado el funeral de Francisco Orozco y Jiménez con el objetivo de que la ceremonia sirviera para unir a los católicos jaliscienses de todas las ramas de la sociedad, y de todos los matices políticos. Al erguirse no sólo como el coordinador del evento luctuoso sino por encima de todo, como el sucesor "ideológico" de Francisco Orozco y Jiménez, José Garibi Rivera buscó convencer a propios y extraños de que en lo sucesivo debían seguir sus consejos y mandatos.

Durante la procesión los fieles se unieron y desaparecieron las diferencias sociales. Es pertinente citar a este propósito al sociólogo Émile Durkheim:

Cuando un individuo muere, el grupo familiar al que pertenece se siente disminuido y, para reaccionar contra esta disminución, se reúne. Una desgracia común tiene los mismos efectos que la cercanía de un acontecimiento

\footnotetext{
${ }^{82}$ J. Ignacio Dávila Garibi, Apuntes para la Historia de la Iglesia en Guadalajara, 5, 230.

${ }^{83}$ Benjamín Ruelas Sánchez, "Frente a la muerte", 138.
} 
feliz: aviva los sentimientos colectivos que, a su vez, llevan a que los individuos se busquen y se aproximen. Hemos visto incluso cómo esa necesidad de concentración se afirma a veces con una energía particular: la gente se abraza, se estrecha, se junta lo más que puede entre sí. ${ }^{84}$

Con el duelo, la familia católica jalisciense experimentó una "impresión de debilitamiento" al sentir en carne viva la pérdida de uno de sus miembros más célebres. Pero la misma impresión de debilitamiento, siguiendo el argumento de Durkheim, llevó a esa familia a cerrar filas, a aproximarse entre sí, a relacionarse más estrechamente, a asociarse "en un mismo estado espiritual" que conllevaba "una sensación de consuelo que compensa el inicial debilitamiento":

Al llorar en común todos se unen entre sí y la colectividad, a pesar del golpe que la ha abatido, no resulta mermada. Sin duda, entonces, no se ponen en común más que emociones tristes; pero comulgar en la tristeza sigue siendo una comunión, y toda comunión de conciencias, con independencia de la forma que adopte, eleva la vitalidad social. La violencia excepcional de las manifestaciones en que necesaria y obligatoriamente se exterioriza el dolor común es en sí testigo de que la sociedad se encuentra, en ese momento, más viva y en acto que nunca. ${ }^{85}$

Mientras, la jerarquía eclesiástica mostró que para la Iglesia católica -ahora encabezada por José Garibi Rivera-importaba subrayar la unión y obediencia de todos los católicos, así como enfatizar la continuidad simbólica de la Iglesia que tuteló, durante 23 años, Francisco Orozco y Jiménez. ${ }^{86}$

Fue precisamente debido a ese fortalecimiento, a ese duelo que ayudó a superar el otro duelo-el de los católicos que se sentían traicionados por

${ }^{84}$ Émile Durkheim, Las formas elementales de la vida religiosa, 271.

${ }^{85} \mathrm{Ibid} ., 374$.

${ }^{86}$ Dadas las muchas desavenencias políticas que existieron entre Orozco y Jiménez y Garibi Rivera, no convenía al segundo que se interpretara la nueva situación como una excusa para vengarse de su antecesor. De hecho, el que Garibi Ribera haya cedido parte de su cripta familiar al arzobispo Orozco y Jiménez, muestra hasta qué punto el primero se esforzó por aparentar que, pese a sus diferencias con el arzobispo, para la hora de su muerte ya lo había perdonado por completo. 


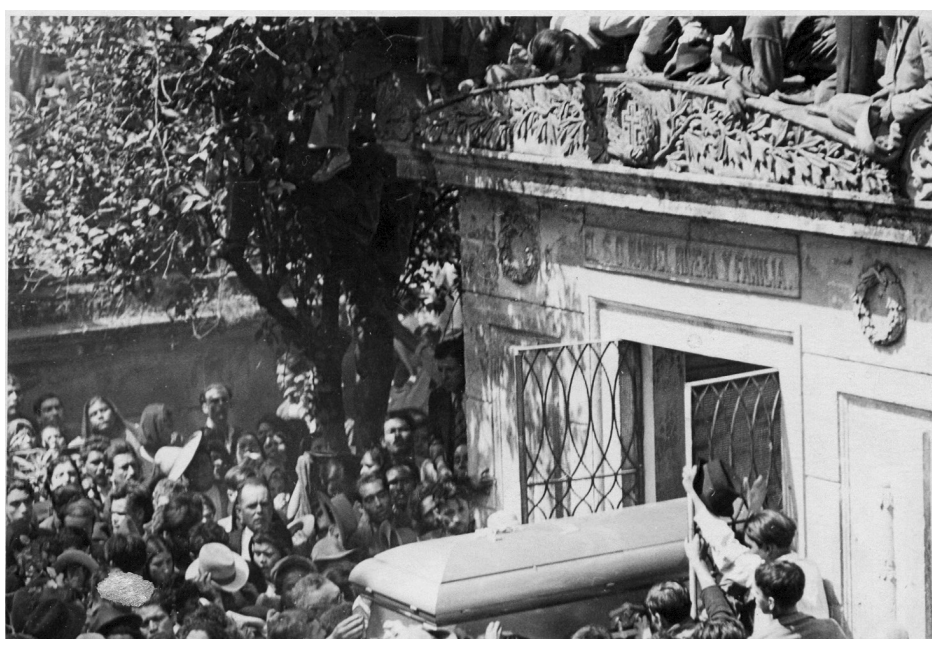

Foto 5. La cripta familiar. Fuente: H2-047b, Centro Documental de las Artes de Jalisco, Dirección de Investigaciones Estéticas, Dirección General de Patrimonio Cultural, Secretaría de Cultura del Gobierno del Estado de Jalisco.

sus jerarcas- me atrevo a aseverar, lo que los unificó en su gran mayoría y los alejó, de una vez por todas, de los caminos que los más subversivos de entre ellos habían elegido por cuenta propia: el de los fusiles. No es coincidencia que a partir de ese mismo 1936 muchos abandonaran las armas para siempre y que a poco más de un año un grupo de jesuitas fundara, con la anuencia de los jerarcas de la Iglesia y la participación multitudinaria de los católicos legos, una organización paraguas que habría de unir en un sólo cuerpo a todos los católicos: la Unión Nacional Sinarquista. ${ }^{87}$

Una etapa insumisa había culminado y no quedaba sino una siguiente fase: la de reconciliación con el Estado mexicano y, por ende, la de la paz. Orozco y Jiménez, sería recordado, es cierto, no como un re-

${ }^{87}$ Servando Ortoll, "Faccionarismo episcopal”, passim; Servando Ortoll. "Las legiones, la Base y el Sinarquismo ¿tres organizaciones distintas y un solo fin verdadero? 1929$1948^{\prime \prime}$, en El PDM, movimiento regional, coordinado por Jorge Alonso, 17-63, Guadalajara, Universidad de Guadalajara, 1990; Servando Ortoll, "Catholic Organizations in Mexico's National Politics and International Diplomacy, 1924-1942", Tesis de doctorado, Columbia University, 1987. 
presentante de la Iglesia cuyo ejemplo había de ser emulado, sino como un individuo que había vivido (y sobrevivido) a través de una época de lucha constante contra las autoridades instituidas, pero que ahora habría de ser remplazado por alguien que-descollando por encima de todo conflicto y desavenencia con el gobierno estatal y nacional-buscaría la armonía y la tranquilidad para todos los católicos de la arquidiócesis.

Pocos años después de la muerte de Orozco y Jiménez, las relaciones de la Iglesia en Jalisco con el gobierno civil local -especialmente con Marcelino García Barragán (1943-1947) y con Jesús González Gallo (1947-1949 y 1949-1953) - y nacional eran de concordia. El arzobispo José Garibi Rivera a lo largo de su administración eclesiástica se vinculó con los gobernadores en turno, y se alió con los comerciantes y empresarios de Jalisco. Así, a partir de los años cuarenta el gobierno, los empresarios, y el arzobispo colaboraron en diferentes ámbitos de la vida local. Garibi Rivera también llegó a un nivel más alto, pues mantuvo buenas relaciones con los sucesivos presidentes de la república. ${ }^{88}$ En esta época a la Iglesia se le permitió que organizara las manifestaciones públicas de culto como misas, desfiles y procesiones. ${ }^{89}$

En 1958, el papa Juan XXIII nombró cardenal a Garibi Rivera, quien para entonces era uno de los jerarcas más importantes dentro del Episcopado..$^{90} \mathrm{El} 29$ de diciembre de 1958, tras recibir el nombramiento en Roma, la ciudad tapatía con sus calles engalanadas, recibió al primer cardenal de México. Esta manifestación de júbilo que inflamó las arterias de la ciudad -feligreses, empresarios y funcionarios del gobierno local se reunieron- recordó los apoteósicos funerales de Francisco Orozco y Jiménez. Garibi Rivera se encargó en 1936 de que el peso de la lápida que cerró la tumba de Orozco y Jiménez, derrumbara también el peso político que cargaba la Iglesia tapatía.

\footnotetext{
${ }^{88}$ Patricia Valles, "José Garibi Rivera: primer cardenal mexicano", 277.

${ }^{89} \mathrm{Ibid} ., 276$.

${ }^{90}$ Ibid., 278.
} 
FuENTES Y BibLIOGRAFÍA

Archivo General de la Nación, Fondo Presidentes Lázaro Cárdenas del Río, México, D.F.

Archivo Histórico de la Arquidiócesis de Guadalajara, Sección Gobierno, Serie Obispos, Francisco Orozco y Jiménez, Guadalajara, Jalisco.

Aguirre Cristiani, Gabriela, "Iglesia y Revolución. Los católicos, el episcopado mexicano y el gobierno de Álvaro Obregón 1920-1924", ponencia presentada en el Congreso Internacional "Dos siglos de revoluciones en México", Morelia, Michoacán, 17 al 20 de septiembre de 2008.

BARBOSA GUZMÁn, Francisco, Jalisco desde la Revolución: la Iglesia y el gobierno civil, Guadalajara, Gobierno del Estado de Jalisco, Universidad de Guadalajara, 1988, vol. 6.

Bautista García, Cecilia Adriana, "Hacia la romanización de la Iglesia Mexicana a fines del siglo XIX", Historia Mexicana LV, 1, 2005, 99-144.

BeEzley, William H. y Linda A. CuRCio, coords., Latin American popular culture: an introduction, Wilmington, Scholarly Resources Inc., 2000.

Ben-Amos, Avner, Funerals, Politics, and Memory in Modern France, 17891996, Oxford, Oxford University Press, 2000.

"The Other World of Memory: State Funerals of the French Third Republic as Rites of Commemoration", en History and Memory 1. 1, 1989, 85-108.

"The Sacred Center of Power: Paris and Republican State Funerals", Journal of Interdisciplinary History 22, 1, 1991, 27-48.

"Patriotism and Popular Culture in the State Funerals of the French Third Republic", en History of European Ideas 16, 4-6, 1993, 459465.

y Eyal Ben-Ari , "Resonance and Reverberation: Ritual and Bureaucracy in the State Funerals of the French Third Republic", en Theory and Society 24, 2, 1995, 163-191.

"El centro sagrado del poder: París y los funerales de Estado republicanos", en Culturales 6, 2007, 49-74.

Camberos Vizcaíno, Vicente, Francisco el Grande. Mons. Francisco Orozco y Jiménez, México, Jus, 1966, vol. 2.

Cuevas Miranda, Alicia, “La política laboral de José Guadalupe Zuno 
1923-1926" en Idem et al., José Guadalupe Zuno Hernández. Vida, obra y pensamiento, Guadalajara, Universidad de Guadalajara, 1991, 123-139.

DÁvILA GARIBI, J. Ignacio, Apuntes para la Historia de la Iglesia en Guadalaja$r a_{L}$ México, Libros de México, 1977, vol. 5.

De LA TORRE, Renée, "La eclesialidad representada en la romería de la Virgen de Zapopan", en Ciencias Religiosas 4, 2001, 39-46.

_ La Ecclesia Nostra. El catolicismo desde la perspectiva de los laicos: el caso de Guadalajara, México, Fondo de Cultura Económica, Centro de Investigaciones y Estudios Superiores en Antropología Social, 2006.

DoRANTES GONZÁLEZ, Alma, "El conflicto universitario en Guadalajara”. Tesis de maestría, Universidad de Guadalajara, 1993.

DuRKHEIM, Emile, Las formas elementales de la vida religiosa en México, México, ediciones Coyoacán, 1995.

Esposito, Matthew D., "Death and Disorder in Mexico City: The State Funeral of Manuel Romero Rubio", en William H. Beezley y Linda A. Curcio, coords., Latin American popular culture: an introduction, Wilmington, Scholarly Resources Inc., 2000, 87-103.

GaLIndo Gaitán, Manuel, Estampas de Guadalajara, Guadalajara, Ediciones Pacífico, 2004, vol. 1.

Garner, Bess Adams, Mexico: Notes in the Margin, Boston, Houghton Mifflin Company, 1937.

GeERTZ, Clifford, Negara. El Estado-teatro en el Bali del siglo XIX, Barcelona, Paidós, 1999.

GoffMAN, Erving, La presentación de la persona en la vida cotidiana, Buenos Aires, Amorrortu editores, 2004.

GonZÁLEZ, Fernando, Matar y morir por Cristo Rey. Aspectos de la cristiada, México, Instituto de Investigaciones Sociales de la UNAM, Plaza y Valdés, 2001.

GRAM, Jorge, La guerra sintética San Antonio, Texas, Rex-Mex, 1937.

Huntington, Richard y Peter Metcalf, Celebrations of Death: The Anthropology of Mortuary Ritual, Cambridge, Cambridge University Press, 1979.

JulliarD, Jacques, coord., La mort du roi: essay d'ethnographie politique comparée, Mesnil-sur-l'Estrée, Gallimard, 1999.

Kertzer, David I. Ritual, Politics, and Power, New Haven, Yale University Press, 1988. 
LóPEZ, Amanda Marie, "El manco y el mártir: funerals, the family, and popular memory of the assassination of Álvaro Obregón, 1928-1929", Tesis de maestría, The University of Arizona, 2004.

Martínez López-CAno, María Pilar, coord., "Tercer Concilio Provincial Mexicano. Anexo II. Estatutos ordenados por el Santo Concilio Provincial Mexicano en el año del Señor de 1589", en Concilios Provinciales Mexicanos, época colonial, en CD-Rom, México, Universidad Nacional Autónoma de México, 2004.

Mc Evor, Carmen, "El regreso del héroe: Bernardo O'Higgins y su contribución en la construcción del imaginario nacional chileno, 1868-1869", en idem.,coord., Funerales Republicanos en América del Sur: tradición, ritual y nación, 1832-1896, Santiago, Centro de Estudios Bicentenario, Pontificia Universidad Católica de Chile, 2006, 125-155.

Meyer, Jean, "Dos Obispos Príncipes, dos hombres una situación", Mi pueblo 131, 2000, 20-23.

Orozco y JimÉnez, Francisco, Memorándum ¡Acerquémonos a Dios!, San Juan de los Lagos, sin editorial, 1918.

Ortoll, Servando, "Faccionarismo Episcopal en México y Revolución Cristera", en Martín de la Rosa y Charles A. Reilly, coord., Religión y política en México, México, Siglo XXI, 1985, 27-41.

"Catholic Organizations in Mexico's National Politics and International Diplomacy, 1924-1942". Tesis de doctorado, Nueva York, Columbia University, 1987.

"Las legiones, la Base y el Sinarquismo ¿tres organizaciones distintas y un solo fin verdadero? 1929-1948", en Jorge Alonso, coord., El PDM, movimiento regional, Guadalajara, Universidad de Guadalajara, 1990, 17-63.

Regalado, Rafael, “Postrer Homenaje”, en J. Ruiz Medrano, coord., Homenaje a la memoria de Excmo. y Rumo. Sr. Dr. Mtro. D. Francisco Orozco y Jiménez arzobispo de Guadalajara, Guadalajara, Imprenta Font, 1936, $42-47$.

RuBEnsteIn, Anne, "Bodies, Cities, Cinema: Pedro Infante's Death as Political Spectacle", en Gilbert Joseph, Anne Rubenstein y Eric Zolov, coords., Fragments of a Golden Age: The Politics of Culture In Mexico Since 1940, Durham, Duke University Press, 2001, 199-233. 
Ruelas SÁnchez, Benjamín, "Frente a la muerte", en J. Ruiz Medrano, coord., Homenaje a la memoria de Excmo. y Romo. Sr. Dr. Mtro. D. Francisco Orozco y Jiménez arzobispo de Guadalajara, Guadalajara, Imprenta Font, 1936, 95-139.

Ruzz Medrano, J., coord., Homenaje a la memoria del Excmo. y Rumo. Sr. Dr. y Mtro. D. Francisco Orozco y Jiménez, arzobispo de Guadalajara, Guadajara, Imprenta Font, 1936.

SCHWARTZ, Barry, "Mourning and the Making of a Sacred Symbol: Durkheim and the Lincoln Assasination", en Social Forces 70.2., 1991, 343-364.

SIN AUTOR, "A la memoria del amado padre desaparecido, el Excmo. Y Rvdmo. Sr. Dr. y Maestro Don Francisco Orozco y Jiménez", en Labor 28, 1936, 4-66.

Salazar, José, "Mons. Orozco y el Pontificio Colegio Pio Latino-Americano" en J. Ruiz Medrano coord., Homenaje a la memoria de Excmo. y Rumo. Sr. Dr. Mtro. D. Francisco Orozco y Jiménez arzobispo de Guadalajara, Guadalajara, Imprenta Font, 1936, 157-162.

TURNER, Victor, "Social Dramas and Ritual Metaphors", en idem., Dramas, Fields, and Metaphors: Symbolic Action in Human Society, Ithaca, Cornell University Press, 1974, 23-59.

Valles, Patricia, "José Garibi Rivera: primer cardenal mexicano", en Carlos Martínez Assad, coord., A Dios lo que es de Dios, México, Aguilar, 1994, 267-285.

VILLASEÑOR Y VILLASEÑoR, Ramiro, Epigrafía del panteón de Belén, Guadalajara, Gobierno del estado de Jalisco, 1985.

FECHA DE RECEPCIÓN DEL ARTículo: 21 de julio de 2009

FECHA DE ACEPTACIÓN Y RECEPCIÓN DE LA VERSIÓN FINAL: 24 de abril de 2010 